\title{
O QUE SE VÊ NAS FAÍSCAS: SOBRE FORMAÇÕES DISCURSIVAS ANTAGÔNICAS, HETEROGENEIDADE ENUNCIATIVA E ENUNCIADO DIVIDIDO ${ }^{i}$
}

\author{
Rudá da Costa Perini \\ Doutorando em Estudos de Linguagem pela Universidade Federal Fluminense (UFF) \\ Bolsita CAPES \\ ruda_perini@hotmail.com
}

\section{RESUMO}

O presente artigo, ancorado na Análise do Discurso materialista, disciplina teóricoanalítica que tem Michel Pêcheux como referência fundadora, propõe uma articulação teórica entre as noções de heterogeneidade enunciativa (AUTIHERREVUZ, 1990) e enunciado dividido (COURTINE, [1981] 2014). Essa articulação constitui-se como uma lente para observar os choques entre formações discursivas antagônicas no discurso jornalístico sobre política. Nessa visada, serão analisados enunciados que, produzidos pelo discurso jornalístico, fazem circular dizeres sobre a votação de abertura do processo de impedimento instaurado contra Dilma Rousseff em abril de 2016.

Palavras-chave: Análise do Discurso; formações discursivas; heterogeneidade enunciativa; enunciado dividido.

\begin{abstract}
This article, anchored in the Materialist Analysis of the Discourse, theoreticalanalytical discipline that has Michel Pêcheux as a reference, proposes a theoretical articulation between the notions of enunciative heterogeneity (AUTIHER-REVUZ, 1990) and divided statement (COURTINE, [1981] 2014). This articulation constitutes as a lens to observe the clashes between antagonistic discursive formations in the journalistic discourse. Thus, in the journalistic discourse, we will analyze statements about the process of impeachment brought against Dilma Rousseff, taking as a focal point the opening vote of the process in the Congress.
\end{abstract}

Keywords: Discourse Analysis; discoursive formation; enunciative heterogeneity; divided statement. 


\section{Considerações iniciais}

Diante de um cenário político marcadamente polarizado, a linguagem se mostra um espaço privilegiado para observar as variadas ressonâncias de grandes distensões no tecido social. Uma dessas ressonâncias é o confronto entre discursos. Com isso em vista, este trabalho se propõe a analisar o funcionamento de enunciados divididos no discurso jornalístico sobre o processo de impedimento instaurado contra Dilma Rousseff em 2016. A discussão feita e as análises apresentadas se amparam no arcabouço teórico da Análise do Discurso materialista (AD), seguindo Michel Pêcheux, Eni Orlandi e outros.

Nessa perspectiva, o discurso é conceito fundamental, o qual é compreendido, segundo Pêcheux ([1969] 1997, p. 81-82), como efeito de sentido entre locutores. Dessa maneira, todo discurso se constitui no encontro do interdiscurso - uma dispersão de discursos outros que torna possível o dizer - com o intradiscurso - o que se formula no momento da enunciação - em condições de produção dadas, o que envolve o sujeito, a conjuntura sócio-histórica e conjuntura imediata do dizer.

Para proceder à análise, trabalhou-se com um material selecionado no qual se recortou, empregando procedimentos metodológicos, um grupo de sequências discursivas exemplares do discurso em tela segundo critérios, inquietações e questões de pesquisa. O corpus analisado foi construído a partir de edições digitais dos jornais Brasil de Fato e $O$ Globo (18/04/2016) nos quais foi noticiada a votação de admissibilidade do processo de impedimento que viera a depor a ex-presidenta Dilma. Entendemos que a votação se configura como um acontecimento histórico e jornalístico, e o modo como é discursivizada configura o que apontamos como um referente discursivo (do que se fala), 
aqui indicado como impeachment/golpe, em outras palavras, analisamos como os jornais significam o impeachment/golpe.

É mister breve explicação sobre esses dois pontos.

Primeiro, sobre as noções de acontecimento histórico e acontecimento jornalístico. Entenda-se por acontecimento histórico, consoante a Le Goff (1996, p. 10), um fato relevante que se inscreve na história pelo trabalho do historiador compondo, portanto, o passado, a memória de uma sociedade. Por acontecimento jornalístico, "um fato que gera uma notícia, que por sua relevância perante a avaliação dos jornalistas do que se constitui como interesse público, merece estar presente nas edições diárias dos noticiários impressos ou eletrônicos" (DELA-SILVA, 2008, p. 15). Interessa destacar o que esses dois conceitos iluminam: nem o fato histórico nem a notícia são constitutivamente objetivos - o que vai de encontro a certa visão cristalizada que sustenta uma suposta objetividade seja do fato histórico, seja da notícia - porque há um sujeito que dá sentido ao fato. O sujeito, para a AD, não é o sujeito cartesiano, da certeza, mas o sujeito dividido pelo inconsciente, interpelado pela ideologia e por isso está sujeito tanto ao equívoco, quanto ao efeito de evidência constitutivo do dizer. Portanto, "não há 'fato' ou 'evento' histórico que não faça sentido, que não peça interpretação, que não reclame que the achemos causas e consequências" (HENRY, 2014, p. 55, aspas do autor). O sujeitohistoriador, o sujeito-jornalista, enfim, o sujeito interpreta sempre de uma dada posição, sempre constituído pelo inconsciente e interpelado pela ideologia.

Segundo, sobre o referente discursivo. Entendemos, a partir de Mariani (1996), que o referente discursivo se constrói no movimento de denominar. Denominar 
ordem da língua ou das coisas, mas organiza-se na ordem do discursivo, o qual, relembrando mais uma vez, consiste na relação entre o linguístico e o histórico-social, ou entre linguagem e exterioridade (MARIANI, 1996, p. 138).

O acontecimento o qual os jornais noticiam é denominado de diferentes modos, inscrevendo diferentes redes de sentido. Por esse motivo, temos um referente discursivo cindido (por isso a barra) que traduz a significação do acontecimento por posições discursivas opostas. Isto é, optou-se pela forma impeachment/golpe no intuito de não perder de vista que o movimento de dar sentido aqui é marcado por uma disputa linguística que reflete as condições de produção em que se inscreve - condições de produção em que discursos produzidos por distintas posições se mostram beligerantes.

Observando tais discursos produzidos por jornais alinhados a posições políticas divergentes, nos deparamos com uma série de enunciados divididos. Assim, apostamos na articulação entre esse conceito e o de heterogeneidade enunciativa a fim de propor a seguinte reflexão teórica: pensar o enunciado dividido como uma forma de heterogeneidade enunciativa mostrada.

Logo, almeja-se, por um lado, aventar essa proposta de articulação teórica, e, por outro, analisar o funcionamento de alguns enunciados divididos que comparecem no corpus.

\section{Adensando a discussão teórica}

Para chegar ao cerne de nossa discussão, é preciso traçar um percurso teórico a fim de fazer relações entre conceitos, conectar pontos. Assim, partimos das noções de 
formação discursiva (FD) e heterogeneidade enunciativa para, adiante, alinhá-las ao conceito de enunciado dividido.

Foucault ([1969] 2016), pensando sobre os muitos aspectos do discurso, formula um conceito de FD que veio a ser absorvido e deslocado por Pêcheux, passando a compor o dispositivo teórico ${ }^{\mathrm{ii}}$ da AD. Em Foucault, lemos:

No caso em que se puder descrever, entre um certo número de enunciados, semelhante sistema de dispersão, e no caso em que entre os objetos, os tipos de enunciação, os conceitos, as escolhas temáticas, se puder definir uma regularidade (uma ordem, correlações, posições e funcionamentos, transformações), diremos, por convenção, que se trata de uma formação discursiva [...] (FOUCAULT, [1969] 2016, p. 47, aspas do autor).

Foucault anunciara a premissa fundamental do funcionamento das FDs: a regularidade. Ainda com o autor, ficamos sabendo que as formações discursivas seguem regras de formação as quais são definidas como:

[...] as condições a que estão submetidos os elementos dessa repartição (objetos, modalidade de enunciação, conceitos, escolhas temáticas). As regras de formação são condições de existência (mas também de coexistência, de manutenção, de modificação e de desaparecimento) em uma dada repartição discursiva (FOUCAULT, [1969] 2016, p. 47).

Dessas regras de formação podemos extrair outra premissa fundamental: a possibilidade de desregulação. Por conseguinte, a condição paradoxal de existência de uma FD é formar-se por regularidades abrigando a possibilidade de se desregular. A partir de Foucault, a noção foi reformulada por Pêcheux e articulada a dois outros conceitos, a saber: condições de produção e interdiscurso. Uma FD passa assim a ser entendida como aquilo que determina 
o que pode e deve ser dito (articulado sob a forma de uma harenga, um sermão, um panfleto, uma exposição, um programa) a partir de uma posição dada numa conjuntura dada, isto é, numa certa relação de lugares no interior do aparelho ideológico, e inscrita numa relação de classes. Diremos, então, que toda formação discursiva deriva de condições de produção específicas [...] (PÊCHEUX; FUCHS, [1975] 1997, p. 166-167, grifos dos autores).

Nessa direção, as FDs articulam em seu interior três processos: as redes parafrásticas, estabilizando sentidos; a polissemia, promovendo rupturas; e os préconstruídos, conferido os sentidos tomados pelo sujeito, identificado com a FD, como evidentes, como "sempre aí". Conforme explica Soares, há, na FD,

A paráfrase - em que enunciados são retomados e reformulados em um esforço de fechamento de suas fronteiras na busca da preservação de sua identidade. A polissemia - em que as fronteiras de uma FD são rompidas, instalando a multiplicidade de sentidos. "Embaralhando", segundo ORLANDI (1983), os limites entre FD' s [...]. O pré-construído remete assim às evidências através das quais o sujeito dá a conhecer os objetos de seu discurso: "o que cada um sabe ou pode ver em uma situação dada e determina o que pode ser dito" (SOARES, 2006, p. 28, aspas do autor).

Assim, a FD é o que determina, numa conjuntura dada, o que pode e deve ser dito e ainda o que não pode e não deve ser dito. São as FDs que regulam "a referência à interpelação-assujeitamento do indivíduo em sujeito de seu discurso" (COURTINE, 2016, p. 38). Como consequência, "os sujeitos falantes, tomados na história, [podem] estar de acordo ou se confrontar sobre o sentido a dar às palavras, falar diferentemente embora falem a mesma língua" (COURTINE, 2016, p. 38) porque "uma FD não é 'uma linguagem 
para todos', tampouco 'cada um com sua linguagem', mas 'as linguagens em um mesmo'" (COURTINE, 2016, p. 39, grifos do autor).

Courtine considera uma FD como heterogênea em relação a si mesma. Para o autor, ela não se fecha completamente. Sua margem é inacabada, logo "não consiste em um limite traçado de uma vez por todas que separa um interior e um exterior, mas se inscreve entre diversas FDs como uma fronteira que se desloca em função das questões de luta ideológica" (COURTINE, 2016, p. 39, grifos do autor). Define-se, dessa maneira, as FDs como regiões situadas no interdiscurso, sendo o interdiscurso que (re)configura suas fronteiras, isto é, "o interdiscurso de uma formação discursiva pode assim ser tomado como o que regula o deslocamento de suas fronteiras" (COURTINE, 2016, p. 40, grifos do autor). Uma FD se constitui por pontos de heterogeneidade dada a movência de suas bordas. Esses pontos de heterogeneidade são característicos tanto das FDs quanto do próprio discurso.

No corpus, após análises, interpreta-se que se configuram duas FDs iii dominantes. Elas se comportam como antagônicas, o que, em grande medida, se deve ao posicionamento da linha editorial dos jornais, portanto, à posição discursiva ocupada por eles. Nessa direção, entende-se que as palavras impeachment e golpe - denominações empregadas para significar de diferentes modos o acontecimento em tela - iluminam a disputa entre posições discursivas que se inscrevem naquelas FDs, nas condições de produção dos discursos produzidos pelos jornais, e parecem funcionar como marcadores de posição que vão estabilizando sentidos. Contudo, isto não se dá sem falhas.

Logo, assinala-se ao menos uma FD dominante em cada jornal: FD1, dominante em $O$ Globo; e FD2, dominante em Brasil de Fato. Cada qual com suas regularidades, paráfrases, rupturas e pré-construídos que, em conjunto, tornam possível identificá-las. 


\section{A aposta teórica: articulando heterogeneidade enunciativa e enunciado dividido}

A heterogeneidade, segundo Authier-Revuz (1990), consiste nas formas em que se faz presente o outro no discurso. Conforme a autora, a heterogeneidade do discurso pode ser constitutiva ou mostrada.

A constitutiva é a própria condição de constituição do discurso. Em todo discurso, ainda que se apresente como homogêneo, há sempre o Outro aí inscrito - este Outro com maiúscula corresponde ao (não) lugar do inconsciente e do interdiscurso, sendo, pois, o Outro irrepresentável. A homogeneidade do discurso, portanto, é uma ilusão ou efeito necessário à própria produção de discurso. Dessa maneira, a heterogeneidade constitutiva é da ordem da "exterioridade interna ao sujeito e ao discurso, não localizável e não representável no discurso que constitui, aquele do Outro do discurso - onde estão em jogo o interdiscurso e o inconsciente [...]" (AUTHIER-REVUZ, 1990, p. 32). O Outro, do qual nos fala Authier-Revuz, é aquilo que fala antes, em outro lugar; o esquecido, impossível para o sujeito acessar, mas que o constitui enquanto sujeito. Daí a formulação de que todo discurso é fundamentalmente heterogêneo, pois não há discurso sem interdiscurso e inconsciente.

A heterogeneidade mostrada é aquela identificada "como formas linguísticas de representação de diferentes modos de negociação do sujeito falante com a heterogeneidade constitutiva do seu discurso" (AUTHIER-REVUZ, 1990, p. 26). Essa forma ilumina a oposição entre o discurso do um, "este que vos fala", interior, e o discurso do outro - com minúscula, pois se trata do outro localizável, o diferente -, "aquele lá", 
exterior. Com isso, a forma mostrada circunscreve e ao mesmo tempo opõe o outro, o heterogêneo, ao restante do discurso que se pretende homogêneo. Ela aponta, então, para o exterior delimitando o interior. Essa forma de heterogeneidade é organizada em duas formas derivadas: a heterogeneidade mostrada marcada e a não marcada. Baalbaki, a respeito das formas marcada e não marcada, assim escreve:

As formas marcadas de heterogeneidade mostrada (discurso direto, discurso indireto, aspas, etc.) representam uma negociação com as forças da heterogeneidade constitutiva que, pela construção de desconhecimento desta, produzem uma representação ilusória, porém necessária, para que o discurso possa ser mantido. As formas não marcadas de heterogeneidade mostrada (discurso indireto livre, ironia, etc.) representam uma outra maneira de negociação com a heterogeneidade constitutiva. Trata-se de uma forma mais arriscada, pois joga com a diluição do outro no um (BAALBAKI, 2010, p. 82).

Como apontado mais acima, nosso corpus é clivado pela disputa entre posições discursivas, o que se marca, dentre outros funcionamentos, no emprego das palavras impeachment e golpe, no uso de uma linguagem beligerante ao falar sobre o acontecimento, e, o que mais interessa aqui, o comparecimento de enunciados divididos - um conceito que explora as relações de antagonismo entre FDs no fio do discurso.

Como dito anteriormente, todo discurso é heterogêneo. Em todo dizer o Outro e o outro habitam e intervém de diversas formas. Este aspecto do discurso é o que AuthierRevuz (1990) chama de heterogeneidade enunciativa constitutiva ou mostrada. Essa última pode ainda ser mostrada marcada ou não marcada. O que se propõe é pensar as formas marcada e não marcada aliadas ao enunciado dividido. Um enunciado dividido seria, pois, a materialização da heterogeneidade mostrada, iluminando os nós do heterogêneo entre formações discursivas. 
Nessa visada, um enunciado dividido, por sua forma sintática, seria um modo de organização de heterogeneidade mostrada. Courtine ([1981] 2014) esquematiza os enunciados divididos na fórmula $\mathrm{P}\{\mathrm{X} / \mathrm{Y}\}$ a qual "provém, efetivamente, da correlação entre duas formulações extraídas de processos discursivos heterogêneos um em relação ao outro, mas de forma sintática determinada" ([1981] 2014, p. 190). Trata-se, segundo o autor, de um enunciado que apresenta "não comutabilidade dos elementos em posição X e Y no contexto de formulação P" (COURTINE, [1981] 2014, p. 191). Em outras palavras, ainda com Courtine, tem-se uma formulação em que há uma fronteira entre formações discursivas marcada "pela identificação contrastiva de elementos de saber antagônicos" ([1981] 2014, p. 193) que vêm "apontar, designar essa fronteira, exibi-la como regra para todo sujeito que deve enunciar ou interpretar tal formulação" ([1981] 2014, p. 193). Em síntese, trata-se de um enunciado que "mostra a presença de dois enunciados distintos, antagônicos entre si; são discursos em confronto que convivem no mesmo enunciado" (CAZARIN, 2000, p. 177).

\section{Breve análise do corpus}

O corpus aqui analisado foi construído a partir de uma edição digital do jornal Brasil de Fato (18/04/2016) e outra de O Globo (18/04/2016). Nele (no corpus) foram empregados os seguintes procedimentos metodológicos: 1) leitura sistematiza buscando mapear enunciados que se referissem ao impeachment/golpe e materializassem o embate entre posições discursivas; 2) recorte e sequenciação de tais enunciados em sequências discursivas; 3) processamento interpretativo-descritivo das sequências 
discursivas. A escolha desse corpus se justifica pelo fato de corresponderem a critérios pré-definidos, a saber: 1) são edições que noticiam o acontecimento tomado como ponto central da investigação (a votação do processo na Câmara dos Deputados); 2) são jornais que produzem uma autoimagem de que tem posicionamento político oposto - o que, entre outros processos, se marca, em $O$ Globo, no funcionamento da denominação impeachment que estabiliza o sentido jurídico-legal, e, em Brasil de Fato, no funcionamento da denominação golpe, que rompe com o sentido jurídico-legal e instaura o sentido de ardil-ilicitude; 3 ) são jornais que pertencem a esferas midiáticas distintas ( $O$ Globo é considerado um veículo da chamada grande mídia e Brasil de Fato é considerado uma mídia alternativa).

Como já apontado, o corpus analisado é marcadamente cindido pela disputa entre posições discursivas. E essa disputa pode ser apreendida em enunciados que, por sua vez, inscrevem-se em FDs antagônicas. Vejamos as seguintes sequências discursivas (SDs):

SD1(OG) Se por um lado o impeachment está longe de ser golpe e é totalmente aceitável em termos legais e pragmáticos, por outro foi conduzido por gente que, na gíria da PM do Rio, está mais suja que pau de galinheiro (PADILHA, José. O Globo, 18 abr. 2016. A cabeça do Lula, País, coluna, p. 27).

SD2(OG) Logo, inexiste qualquer justificativa razoável para o Senado não dar início à fase de julgamento da presidente com urgência máxima, obedecidos todos os trâmites legais, com respaldo do STF. Chega a ser uma questão de segurança nacional ( $O$ Globo, 18 abr. 2016. Um passo para o impeachment, Opinião, p. 18).

SD1(BF) É visível em todas as manifestações que estão ocorrendo que o sonho de um novo Brasil pulsa e já não cabe nas velhas roupas que usa. Esse novo Brasil não sairá de um golpe. Sairá do povo nas ruas, da união, da luta organizada. A história nos trouxe até aqui e é hora de assumir 
nosso papel (Brasil de Fato, 18 a 20 abr. 2016. Novo Brasil não sairá de um golpe, Opinião, p. 3).

SD2(BF) No entanto, mais que isso, a missão de Temer é aumentar a exploração aos trabalhadores para que os empresários tenham mais lucro. Na cabeça deles, com o empresário tendo mais lucro a economia vai crescer. Mas isso não acontece na realidade. [declaração de João Pedro Stedile (direção do MST)] (Brasil de Fato, 18 a 20 abr. 2016. "Até coxinhas farão ato contra Temer", diz Stedile, Entrevista, p. 5).

Destacam-se nas SDs acima enunciados divididos que se configuram como heterogeneidade mostrada não marcada - aquela que está para a alusão, a ressalva, o discurso indireto livre, a ironia, entre outras. Na SD1(OG) lemos "Se por um lado o impeachment está longe de ser golpe e é totalmente aceitável". Aqui o discurso-outro intervém, e, apesar de ser repelido, instaura divisão produzindo efeitos no enunciado, pois dizer "o impeachment está longe de ser golpe" é também dizer sem dizer que é golpe, bem como dizer que "é totalmente aceitável" também é dizer que não é; aí irrompe a contradição. Ou seja, no enunciado acima, duas FDs coabitam, como escreve Courtine, em não comutabilidade de modo que o dizer do outro é dito apenas para ser refutado. Portanto, temos nas quatro SDs, como analisaremos adiante, modos de negar o outro, isto é, negar partes de discursos outros que precisam ser demarcadas como heterogêneas.

No mesmo enunciado comparecem " $\mathrm{X} / \mathrm{Y}$ ", um enunciado produzido em FD1 se confronta com outro oriundo de FD2: 


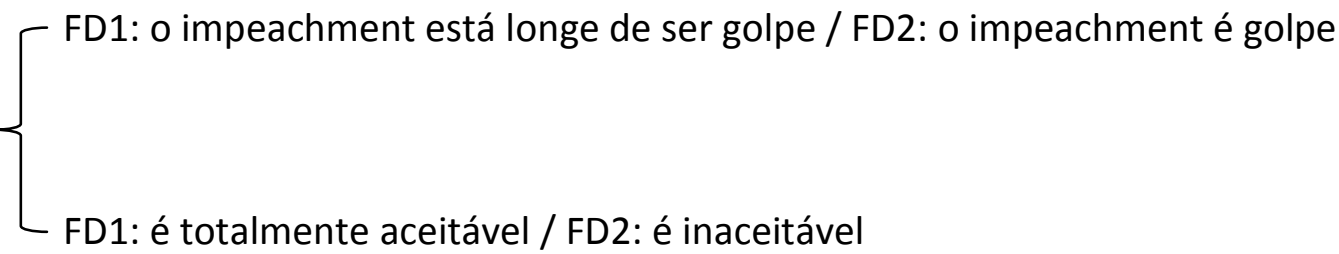

O termo "está longe" demarca afastamento, uma negação de "o impeachment é golpe"; em seguida, a afirmação categórica "totalmente aceitável", na qual o advérbio totalmente tenta fechar as fronteiras da FD, interdita outra posição, aquela silenciada que diz "é inaceitável".

O enunciado dividido se configura, muitas vezes, pela negação, isto é, no movimento de trazer o discurso-outro e negá-lo. Assim, citando mais uma vez Courtine, isto

[...] vêm materializar em discurso as formas nas quais a luta ideológica se manifesta na luta política: como guerra ideológica de posição, onde a refutação faz-se "por denegação" (imitar as palavras do outro, opor suas palavras às do outro, lutar palavra por palavra, como se avança passo a passo numa guerra de trincheiras) (COURTINE, [1981] 2014, p. 209, aspas do autor).

A negação configura-se, desta forma, como um modo de cerzir o outro, o diferente, o exterior, no interior do discurso, mas deixando às claras as marcas e relevos da costura. Ou seja, "a negação é um dos processos de internalização de enunciados oriundos de outros discursos" (INDURSKY, 1992, p. 307). Com isso, demarca, ilumina a fronteira entre o que pode/deve ser dito e o que não pode/não deve ser dito. 0 que tentamos sinalizar é justamente o postulado por Courtine através da fórmula $P\{X / Y\}$. Pela negação se inscreve o discurso outro, o negado, no seio do próprio enunciado de tal 
forma que ali $(P)$ os dois $(X / Y)$ coabitem em não comutabilidade, disputando o espaço da interpretação.

Indursky (1992), no tocante à negação, distingue três operações discursivas diferentes; a negação externa, negação interna, e negação mista:

a negação externa, que incide sobre o que não pode ser dito no interior de FD1, a negação interna, que incide sobre o que pode mas não deve ser dito neste domínio de saber e a negação mista, que mobiliza as duas modalidades anteriores numa única operação de negação (INDURSKY, 1992, p. 309-310, grifos da autora).

Nas quatro SDs acima estamos lidando com a modalidade de negação externa, aquela que, segundo Indursky, "incide sobre um discurso que provém de uma formação discursiva adversa" (1992, p. 310) podendo, ainda, se materializar em marcadores de negação "tais como: advérbio de negação não; prefixos de negação in, des; itens lexicais do tipo recusar, impedir; pronomes indefinidos como jamais, ninguém" (1992, p. 311, grifo da autora).

Em SD2(OG), é possível identificar a construção do enunciado dividido através do prefixo in em "inexiste". No enunciado "inexiste qualquer justificativa razoável para o Senado não dar início à fase de julgamento da presidente com urgência máxima", a posição-OG nega a existência de uma justifica razoável para o Senado julgar o processo leia-se que para outra posição, esta justificativa existe e seria justamente a ilegalidade do processo. Assim, nega que existe tal justificativa, mas para se negar que existe é preciso primeiro admitir que existe para se falar sobre ela, caso contrário não seria necessário sequer negar. Aqui podemos representar o enunciado dividido e, por conseguinte, um exemplo de heterogeneidade mostrada não marcada, da seguinte forma: 
FD1: Inexiste justificativa/ FD2: existe justificativa

A próxima SD, SD1(BF), apresenta o funcionamento do não. No enunciado "Esse novo Brasil não sairá de um golpe" vemos o advérbio de negação não como um marcador de negação, de isolamento do outro. Entretanto, neste enunciado, o funcionamento da negação leva a uma relação de sentidos mais complexa. Se dissemos que este não nega o discurso outro, e, como vimos, este outro inscreve-se em FD1, poderíamos dizer que esta outra posição afirma:

FD2: Esse novo Brasil não sairá de um golpe/ FD1: Esse novo Brasil sairá de um impeachment

SD1(BF) nos remete aos processos de significação do impeachment/golpe através de marcadores de posição e como bem podemos perceber, tais processos não são nada simples. Ao dizer "esse novo Brasil não sairá de um golpe" a posição-BF apaga a denominação impeachment direcionando a significação do acontecimento pela denominação golpe. O confronto entre formações discursivas antagônicas neste enunciado coloca em questão a interpretação; a posição-BF, mesmo com os atravessamentos de enunciados oriundos de outra FD, tenta fechar os furos de FD2. Entretanto, os atravessamentos, interferências, alusões, ironias são constitutivos das FD1 e FD2; é na batalha pela palavra que elas se constituem.

Em SD2(BF), lê-se "Na cabeça deles, com o empresário tendo mais lucro a economia vai crescer. Mas isso não acontece na realidade." Aqui estamos diante de dois 
funcionamentos distintos: 1) o uso de discurso indireto livre (eles que dizem isso) demarcado por "na cabeça deles" instaurando um afastamento entre o sujeito que enuncia e o outro; 2) a negação que refuta, "mas isso não acontece na realidade", produzindo o seguinte efeito: "o que eles pensam não acontece assim, portanto, é mentira". O outro é inserido no fio do discurso para ser deslegitimado, desmentido, "o que eles dizem não é verdade". Fica organizada a divisão, pois, da seguinte forma:

FD1: com o empresário tendo lucro a economia vai crescer/ FD2: não é com o empresário tento lucro que a economia vai crescer

\section{Conclusão}

Sem a pretensão de esgotar a discussão a teórica, apresentou-se aqui a primeira formulação de uma proposta que segue como objeto de reflexão. A partir da mobilização articulada das noções de heterogeneidade mostrada e de um enunciado dividido, algumas análises dos discursos de $O$ Globo e Brasil de Fato foram produzidas de modo a dar a ver o funcionamento da alusão, da negação, da retomada do discurso outro, instaurando na língua o embate entre posições discursivas.

Enfim, trouxemos para a análise quatro SDs exemplares do comparecimento de enunciados divididos no discurso jornalístico sobre o impeachment/golpe. Os enunciados divididos materializam o choque entre discursos que disputam o espaço da interpretação dominante, e, nas faíscas, é possível vislumbrar a contradição constitutiva de FDs 
antagônicas. Ou seja, é preciso se distanciar do outro, demarcar o discurso do outro, negar o outro. Contudo para distanciá-lo, demarcá-lo, negá-lo... é preciso dizê-lo.

\section{Referências}

AUTHIER-REVUZ, Jacqueline. Heterogeneidade(s) enunciativa(s). Tradução Celene Cruz e João Wanderley Geraldi. Caderno de Estudos Linguísticos. Campinas, SP: vol. 19, 1990.

BRASIL DE FATO. Rio de Janeiro, 18 a 20 abr. 2016. Disponível em:

<https://issuu.com/brasildefatori/docs/brasil de fato - 171 web $>$. Acesso em: 2 maio 2017.

BAALBAKI, Angela Corrêa Ferreira. A revista Ciência Hoje das Crianças e o discurso de divulgação científica: entre o ludicismo e a necessidade. 2010. Tese (Doutorado em Estudos de Linguagem) - Pós-graduação em Estudos de Linguagem, Universidade Federal Fluminense, Niterói, 2010.

CAZARIN, Ercília Ana. O confronto entre duas posições de sujeito, inscritas em diferentes formações discursivas, marcado linguisticamente pelo enunciado dividido. In: INDURSKY, Freda; CAMPOS, Maria do Carmo. Discurso, memória, identidade. Porto Alegre: Editora Sagra Luzzatto, 2000.

COURTINE, Jean-Jacques. Análise do discurso político: o discurso comunista endereçado aos cristãos. São Carlos: EdUFSCar, 2014 (1981).

COURTINE, Jean-Jacques. "Que objeto para a análise de discurso? In: CONEIN, Bernard et al. (orgs). Materialidades discursivas. Campinas: Editora da Unicamp, 2016.

DELA-SILVA, Silmara Cristina. O acontecimento discursivo da televisão no Brasil: a imprensa na constituição da TV como grande mídia. 2008. Tese (Doutorado em Linguística) - Pós-Graduação em Estudos da Linguagem, Universidade Estadual de Campinas, Campinas, 2008.

FOUCAULT, Michel. Arqueologia do saber. 8. ed. Rio de Janeiro: Forense Universitária, 2016 (1969).

HENRY, Paul. A história não existe?. In: ORLANDI, Eni (org.). Gestos de leitura: da história no arquivo. 4. ed. Campinas, SP: Editora da Unicamp, 2014. 
INDURSKY, Freda. A fala dos quarteis e outras vozes: uma análise do discurso presidencial da terceira república brasileira (1964-1984). 1996. Tese (Doutorado em Linguística) Instituto de Estudos da Linguagem, Universidade Estadual de Campinas, Campinas, SP, 1992.

LE GOFF, Jacques. História e memória. 4. ed. Campinas, SP: Editora da Unicamp, 1996.

MARIANI, Bethania Sampaio Corrêa. O comunismo imaginário: práticas discursivas da imprensa sobre o PCB (1922-1989). 1996. Tese (Doutorado em Linguística) - PósGraduação em Estudos da Linguagem, Universidade Estadual de Campinas, Campinas, 1996.

O GLOBO. Rio de Janeiro, 18 abr. 2016. Primeiro Caderno. Disponível para assinantes em: $<$ https://acervo.oglobo.globo.com/consulta-aoacervo/?navegacaoPorData=201020160418 > . Acesso em: 2 maio 2017.

ORLANDI, Eni Puccinelli. Análise de Discurso. In: ORLANDI, Eni Puccinelli. Introdução às ciências da linguagem: discurso e textualidade. Campinas, SP: Pontes Editores, 2006.

PÊCHEUX, Michel; FUCHS, Catherine. A propósito da análise automática do discurso: atualização e perspectivas (1975). In: GADET, Françoise; HAK, Tony. (orgs.). Por uma análise automática do discurso: uma introdução à obra de Michel Pêcheux. 3. ed. Campinas, SP: Editora da Unicamp, 1997.

PÊCHEUX, Michel. Análise automática do Discurso (AAD-69). In: GADET, Françoise; HAK, Tony. (orgs.). Por uma análise automática do discurso: uma introdução à obra de Michel Pêcheux. 3. ed. Campinas, SP: Editora da Unicamp, 1997.

PERINI. Rudá da Costa. 2019. Dissertação (Mestrado em Estudos de Linguagem) - PósGraduação em Estudos de Linguagem, Universidade Federal Fluminense, Niterói, 2019.

SOARES, Alexandre Sebastião Ferrari. A homossexualidade e a AIDS no imaginário de revistas semanais (1985-1990). 2006. Tese (Doutorado em Estudos de Linguagem) Programa de Pós-Graduação em Estudos de Linguagem, Universidade Federal Fluminense, Niterói, 2006.

Recebido em 24 de junho de 2019. Aceite em 06 de novembro de 2019. 
' O presente trabalho foi realizado com apoio da Coordenação de Aperfeiçoamento de Pessoal de Nível Superior - Brasil (CAPES).

"Em AD, fazemos distinção entre o dispositivo teórico e o dispositivo analítico. Como explica Orlandi: "O dispositivo teórico é constituído pelas noções e conceitos que constituem os princípios da análise de discurso: a noção de discurso como efeito de sentidos, a noção de formação discursiva, a de formação ideológica, o interdiscurso, etc. $\mathrm{O}$ dispositivo teórico vai determinar o dispositivo analítico. Ele orienta em como observar o funcionamento discursivo. É o dispositivo teórico que faz o deslocamento de uma leitura tradicional para uma leitura que chamamos sintomática: a que estabelece uma escuta que coloca em relação o dizer com outros dizeres e com aquilo que ele não é mas poderia ser. 0 dispositivo analítico da interpretação é o dispositivo que cada analista constrói em cada análise específica. Determinado pelo dispositivo teórico, o dispositivo analítico por sua vez vai depender da questão do analista, da natureza do material analisado, do objetivo do analista e da região teórica em que se inscreve o analista (linguística, história, antropologia, literatura, etc.)" (2006, p. 30).

iii A compreensão/identificação das FDs que constituem um certo discurso só é possível após a análise, isto é, as FDs não estão dadas a priori. Foi necessário omitir aqui uma série de procedimentos metodológicos empregados para chegar a elas. Para ver de forma mais detalhada a constituição das FDs no corpus em tela, ver Perini (2019). 